\title{
Transition Metal Mobility and Partitioning in Weathered Tailings, Serpentinite and Skarn from the Lord Brassey mine, Tasmania, Australia
}

Makoto J. HONDA-MCNEIL ${ }^{1}$, SiOBHaN A. WIISON ${ }^{1}$, BEN F. MILLILI ${ }^{2}$, NINA ZEYEN ${ }^{1}$, BAOLIN WANG ${ }^{1}$, CONNOR C. TURVEY ${ }^{3}$ AND SIMON M. JOWITT ${ }^{4}$

${ }^{1}$ Department of Earth and Atmospheric Sciences, University of Alberta, Edmonton, AB, Canada

${ }^{2}$ BHP Operating System, 171 Collins Street, Melbourne, VIC, Australia

${ }^{3}$ Bradshaw Research Initiative for Minerals \& Mining, The

University of British Columbia, Vancouver, BC, Canada

${ }^{4}$ Department of Geoscience, University of Nevada, Las Vegas, NV, USA

Ultramafic and mafic mine tailings host heavier elements such as first and second row transition metals and Platinum Group Elements (PGE). Common transition metals in maficultramafic rocks, such as nickel and cobalt, have high value which could act as a motivator for existing mines to reprocess their tailings. Many target metals are initially hosted by olivine, repartitioned during serpentinization to form sulfides, oxides and alloys, and then potentially remobilized during weathering to form authigenic carbonates, sulfates and oxyhydroxides [1]. Economic recovery of transition metals from tailings also has the potential to reduce waste output while enhancing silicate weathering reactions to offset greenhouse gas emissions.

Here we use powder X-ray Diffraction (XRD), Scanning Electron Microscopy (SEM) with Energy Dispersive X-ray Spectroscopy (EDS) and synchrotron X-ray Fluorescence Mapping (XFM) to track the mobility and partitioning of first and second row transition metals in serpentinite, skarn and weathered tailings from the historical Lord Brassey nickel mine in Tasmania, Australia. By developing an understanding of the sinks for metals across the mining lifecycle, we aim to develop an economically viable framework for tailings reprocessing that takes advantage of metal mobility during tailings weathering.

Our SEM-EDS results reveal that awaurite $\left(\mathrm{Ni}_{3} \mathrm{Fe}\right)$ is common at Lord Brassey, occuring as 1-10 $\mu$ m grains. Sulfides contain transition metals such as copper, cobalt, nickel, and cadmium. Elemental tungsten, tin, silver and osmium have also been observed. Our early findings reveal a diverse range of transition metals hosted in Lord Brassey mine tailings and suggest the possibility of economic recovery.

[1] Hamilton, J. L. et al., 2018, IJGGC, 71, 155-167. 